This item was submitted to Loughborough's Research Repository by the author.

Items in Figshare are protected by copyright, with all rights reserved, unless otherwise indicated.

\title{
Sport, physical activity and public health [Editorial]
}

PLEASE CITE THE PUBLISHED VERSION

http://dx.doi.org/10.1080/19406940.2016.1254666

\section{PUBLISHER}

(C) Taylor \& Francis

\section{VERSION}

AM (Accepted Manuscript)

\section{PUBLISHER STATEMENT}

This work is made available according to the conditions of the Creative Commons Attribution-NonCommercialNoDerivatives 4.0 International (CC BY-NC-ND 4.0) licence. Full details of this licence are available at: https://creativecommons.org/licenses/by-nc-nd/4.0/

\section{LICENCE}

CC BY-NC-ND 4.0

\section{REPOSITORY RECORD}

Mansfield, Louise, and Joe Piggin. 2019. "Sport, Physical Activity and Public Health [editorial]”. figshare. https://hdl.handle.net/2134/24058. 


\section{EDITORIAL: Sport, physical activity and public health}

\section{Louise Mansfield \& Joe Piggin}

The aim of this special issue is to encourage critical discussions about the political issues connected to the contemporary role of sport and physical activity in public health. There is evidence of a late twentieth-century resurgence in the importance of physical activity in public health policy. For example, increasingly explicit recommendations on physical activity levels in global health strategies and national physical activity policies and continued and updated position statements from specialist medicine and exercise working groups are available. In addition, local promotion, delivery, governance and monitoring of individual and community-based sport and physical activity programmes are intensifying. While there is an established corpus of policy-orientated research articles on public health and lifestyle factors including physical activity, sport is remarkably absent from the public health research agenda. This omission is evident despite the sport sector currently being a priority area for increasing population rates of physical activity. Very little is known about the contribution of sport to physical activity and health. Whilst there has been extensive and recent investment in policy and practice aspects of physical activity, both in the UK and worldwide, population-level responses have had limited success in arresting the upward trend in inactivity and reducing inequalities in activity levels. The requirements for successful individual, community and national promotion of sport and physical activity programmes are not well understood and there is scope to bring critical work to the fore on the impact and consequences (both intended and unintended) of such programmes for diverse groups of people. The relationships between sport, physical activity and health are not neutral but reflect complex temporal and spatial struggles over political positions, social ideologies, policymaking and policy enactment. It is, thus, timely and significant for this special issue to raise questions and present critical analyses about the politics and policy of the sport/physical activity/health dynamic.

Public health is an established and powerful policymaking sector in the UK and worldwide.

Public health policymaking involves several approaches connected to research and evidencebuilding, 
commissioning and managing, service delivery and public participation in programmes intended to prevent disease, promote health and prolong life at a population level (WHO 2007). This is of course a complicated policy arena. Public health involves various methods of monitoring and evaluation, a range of interventions and many health professionals working with diverse people in varying contexts (Douglas et al. 2007). There is a growing awareness and intensifying morality surrounding the potential public health threats posed by a lack of physical activity as well as the benefits of sustained engagement in physical activity. Much of this narrative is driven by medical and behavioural science. However, some critical research has identified the complex relationships between sport, physical activity and health (Waddington 2000). Other research has addressed the policy dimensions of physical activity, commercialisation and marketing (Piggin 2014, Piggin and Bairner 2014). Some work has explored the complex political arena of sports medicine and health (Malcolm and Scott 2011) and another focus has been on critical understandings of the structures, processes, experiences and health consequences of fitness-based physical activity (Markula 1995, Maguire 2008, Mansfield 2011). Questions about ageing, disability, socio-economic status, ethnicity and gender have also come to the fore in discussions about the policies and politics of sport and physical activity for health (see, for example, Wilkinson and Marmot 2003, Howe 2004, Wray 2007, Phoenix and Grant 2009, Kay and Spaaij 2012). Despite such critiques, stemming from disciplines as varied as social gerontology, the sociology of sport, social psychology, gender studies, international development, policy studies and policy science, there is space for more overt discussions of the increasing relevance and complexities of the politics and policy implications of sport, physical activity and public health.

In this special issue, we include articles from a variety of disciplinary foundations that engage in critical examinations of sport and physical activity allied to public health policy. The papers selected cover both the analysis of policy and analysis for policy (Houlihan et al. 2009), ensuring that a critical focus on the politics of each is at the centre of discussions. Our contributors discuss issues connected to the politics and policy of sport, physical activity and public health by focusing on a range of theoretical themes including evidence and knowledge production, national policies 
and the political promotion of sport and physical activity for health, sports mega-events and public health, social diversity in community sport for health programming, education and training in physical education and fitness sectors, and critical perspectives on partnership working in sport and public health. Overall, the papers reflect debate about the motivations of national and local government intervention in policymaking on public health that includes the role of sport and/or physical activity, and the polemic about the impact that such policy decisions have on people and their communities.

This special issue reflects a current expansion in academic, policy and practice interest in sport and physical activity for public health. There are 11 research articles representing high-quality empirical approaches to advancing knowledge about sport or physical activity and public health. We also include three research notes; shorter discussion pieces drawing attention to particular ideas; and critical perspectives on the promotion of sport for public health improvement. Tess Kay leads the collection by identifying the absence of social science theories and evidence in physical activity policy guidance. More specifically, she argues that there is a perceptible failure in such guidance to recognise and include well-established debates about health inequalities and the social determinants of health despite levels of physical activity being the lowest amongst those in the lower social gradient. Expanding the scope of the knowledge base on physical activity for health, perhaps by bringing together communities of experts in health behaviour research and those working on social science perspectives on the social determinants of health, is proposed as a key step in ensuring a better understanding of the relationship between health inequalities and physical activity. It is also perhaps a route towards better-informed and more relevant physical activity guidance. Taking up a discussion of the relationship between evidence-based policy and the promotion of sport for public health, Mike Weed interrogates evidence for the effectiveness of sport for raising population levels of physical activity and delivering public health outcomes amongst the least active. Analysing UK national survey data, Weed argues that sport participation has stagnated or fallen since 1990 despite continued Government investment and that from 1997, any increases in population levels of physical activity are not associated with sport. Coupled with 
what Weed identifies as a limited evidence-base for the effectives of sport interventions in raising activity levels amongst inactive people, he concludes that national agendas for increasing physical activity for public health should privilege choice of opportunities for a range of physical activities rather than prioritise sport.

Marina Honta presents a discussion of the role of the state in the implementation of the 'Sport, Health and Wellbeing Plan' in France. She identifies inter-ministerial governance as an acclaimed approach to effective enactment of the national plan. However, by Honta's view, the complex and fractured nature of French state departments curtails the possibility of effective implementation of national programming at the local level. Honta argues that inter-ministerial partnerships, and the power struggles that prevail in such cross-government working, have meant that the regional and local implementation of the 'Sport, Health and Wellbeing Plan' is limited. The challenges of raising population levels of physical activity through national programming are also considered in the first of our research notes by Oliver, Hanson, Lindsey and Dodd-Reynolds in a critical commentary about the recent extension of the UK Exercise on Referral programmes to include sport; an approach the authors identify as Sport-based Exercise on Referral. Two important issues are raised: (1) the weak evidence base for supporting exercise on referral means that there is questionable potential to scale up a national programme to include sport; and (2) including sport in exercise on referral schemes may exacerbate existing challenges associated with providing appropriately targeted activities for those with complex barriers to exercising.

Recognition of the complex relationship between sport, physical activity and public health is the subject of Smith, Jones, Houghton and Duffell's paper, which turns the attention of the special issue to mental health. The authors offer an overview of sport, physical activity and mental health policy in England, UK. In it they identify that whilst the use of exercise and other modes of physical activity are an explicit part of health policy goals to prevent and treat mental illness and promote mental health, a focus on mental health is largely absent from national and local sport and physical activity policy. Coupled with a lack of clear practice guidelines, little reference to monitoring and evaluating sport and physical activity for mental health and complex political and funding contexts 
for commissioning physical activity for mental health programmes, the authors conclude there are significant challenges in designing, implementing and evaluating sport and physical activity projects for mental health outcomes. They offer a rallying call to sport and mental health organisations, researchers, programme deliverers and policymakers to address these challenges through community sport policy development, enactment and evaluation.

Presenting a policy content analysis of London 2012's Olympic pre-event documentation on participation legacy, Bretherton, Piggin and Bodet examine the destruction, construction and reconstruction of competing discourses presented by different organisations responsible for legacy delivery. Employing a governmentality framework, the authors identify inconsistencies in the representation of participation legacy which contribute to failings in delivering legacy outcomes. The authors conclude that host governments cannot rely on elusory concepts like 'inspiration' for positive legacy effects of mega-events like the Olympic Games. Strategic approaches that recognise the wider social and political impact on legacy efforts are required for legacy policy to be effectively enacted. In our second research note, Gard and Diongi illustrate how sport, more broadly seen as a social policy instrument, appears to be endlessly flexible and is used to support a range of political and health-based ideologies across the life course. Using examples connected to the political imperative of public health, their discussion illustrates the rhetoric of sport's public health utility. In the context of the so-called crises of obesity, ageing and lifestyle diseases, the authors conclude that sport promotion provides a plethora of opportunities for over-stating the benefits of physical activity and representing dominant public health discourses of self-serving institutions. The contribution by Markula and Chikinda and the third and final of our research notes by Ressler, Richards and Wright focus on the promotion of public health in education and training. Markula and Chikinda's small-scale qualitative study identifies traditional fitness instructors as potential new local public health promoters but highlights incongruity between fitness instructor training and qualifications, and public health priorities. Fitness instructor training, dominated as it is by narrow, exacting and overbearing approaches to fit bodies, and reinforcing medical discourses and models of health based solely on the absence of disease, leave little room for instructors to 
teach and learn about health inequalities, health and social diversity, and more holistic strategies for public health promotion. Offering a discussion of the socio-politics of physical education, sport, schools and health in the USA, Ressler et al. argue that physical education programmes are also failing to make an impact in enhancing public health as they are currently making little impact in increasing physical activity or encouraging active lifestyles. Physical education, it is argued, is marginalised in the curriculum in the USA, dominated by competitive athletic programming and dogged by conflicts over teaching and coaching. The result is the continued exclusion of those not interested in traditional sports and ongoing challenges for physical education as a public health intervention. Ressler et al. do, however, propose a more fruitful dialogue between physical education and public health through knowledge exchange between the sectors and higher expectations and more rigorous accountability of PE as a mechanism for public health.

Our next two contributions shift the emphasis of debate to the complexities of participant experience in selected sport and physical activity opportunities. For Lenneis and Pfister, gender and ethnicity intersect to foreground conceptions of healthy bodies and physical activity in female migrant cleaners in Denmark. The authors emphasise that minority ethnic groups in Denmark are more at risk of ill health than native populations but that little is known about their lifestyle behaviours, including their attitudes to and practices and of physical activity. Exploring the views of female migrant cleaners through in-depth interviews, Lenneis and Pfister identify that weight loss and management are motivating factors for becoming and being physically active but that work and unpaid domestic constraints serve to create often insurmountable barriers to participation. For these authors, policy needs to recognise the constraining features of organised work and the gendered character of unpaid domestic labour in shaping opportunities for and barriers to physical activity for ethnic minority women. Jenkin, Eime, Westerbeck, O'Sullivan and van Uffelen examine the role of sports organisations in promoting and delivering sports for older adults. Focus group research with representatives of the Australian National Sports Organisations (ANSOs) and older people revealed personal and organisational barriers to the engagement of older people in sport but Jenkin et al. argue that these can be countered by a series of identified participation benefits for those in older age groups. The authors conclude that there are emerging opportunities for 
sports clubs to engage older people and the possibility that this demographic can experience health benefits from taking part in sport.

Our final three contributions address issues associated with evidence-building and knowledge production in sport, physical activity and public health partnership work. Watson, Lashua and Trevorrow introduce some of the challenges of developing research-practice partnerships in youth community dance projects where practitioners experience an intensifying requirement for evaluation to demonstrate 'what works' in public health terms. Presenting collective, critical conversations between dance practitioners, academic researchers and local authority commissioners, the authors highlight different disciplinary, dance practice, management, research and public health views that need to be considered in developing relevant and effective approaches to monitoring and evaluating community dance programmes. Ongoing dialogue focused on positioning dance as a meaningful sociocultural activity and a sporting leisure pursuit with innumerable possibilities for health and well-being benefits. Such critical conversations served to navigate a path in a direction away from dominant discourses of 'measuring' the public health impact of dance and towards evaluation strategies that captured the creative, artistic and altogether more innovative possibilities for impact from engagement in practices of dance.

Our final two contributions examine in detail the complexities of partnership working in the current climate of monitoring, evaluation and evidence-building in the sport and public health sectors. Misener and Misener examine the role of sport organisations in public health promotion in Canada using observational and interview methods. They provide a case study of a local crosssector partnership between sport and public health agencies for increasing physical activity for health through a strategic marketing project. Despite the national imperative for sport-public health promotion partnerships, the authors highlight a misalignment in local collaborations as a result of different and competing values, discourses and objectives. For these authors, higher-order priorities emphasising partnerships as a means to achieving public health outcomes underestimate local constraints in capacity in achieving health policy goals. Mansfield focuses on the complexities of collaborative working in knowledge production about sport for public health benefits. Drawing 
on her experiences of working in evidence-building projects involving multiple and diverse stakeholder groups, she explores the competing and converging interests in the roles, responsibilities and values that shape such work. Mansfield identifies resourcefulness, reciprocity and reflexivity as central characteristics of partnership working. She presents them in a conceptualisation of the three Rs of research-policy-practice (RPP) partnerships; a way of understanding and addressing the sociodynamics of partnership work. Mansfield argues her conceptual approach as a way of demythologising the role of sport in achieving public health outcomes via an interrogation of resource allocation, ownership and use in partnerships, and through a thorough analysis of the relationships that characterise them.

We do not wish to suggest that the contributions in this special issue bring the politics and policy issues associated with sport, physical and public health to a close. Rather, we present this collection as a starting point for debate and for the development of research, policy and practice based on the diversity of the arguments proposed. We invite scholars in both sport and public health, alongside stakeholders from policy and practice, to engage with the issues our contributors have raised in advancing knowledge and developing future directions for understanding the politics of sport, physical activity and public health. For us, the current agenda for research on sport, physical activity and public health might best be focused on five areas of work; rigorous empirical studies on sport for public health, critical analyses of knowledge production methods and strategies for evidence building, assessments of partnership working in the design, delivery and evaluation of sport for health programmes, critical policy analysis where sport is prioritised for public health objectives, and examinations of the place and status of sport and physical activity in wider political agendas for public health, particularly in relation to current concerns about mental health and well-being.

\section{References}

Douglas, J., et al., 2007. A reader in promoting public health. London: Sage. Houlihan, B., Bloyce, D., and Smith, A., 2009. Developing the research agenda in sport policy. International journal of sport policy and politics, 1, 1-12. doi:10.1080/19406940802681186

Howe, P.D., 2004. Sport, professionalism, and pain: ethnographies of injury and risk. Psychology Press. New York, NY: Routledge.

Kay, T. and Spaaij, R., 2012. The mediating effects of family on sport in international development contexts.

International review for the sociology of sport, 47 (1), 77-94. doi:10.1177/1012690210389250

Maguire, J.S., 2008. Fit for consumption: sociology and the business of fitness. London: Routledge. 
Malcolm, D. and Scott, A., 2011. Professional relations in sport healthcare: workplace responses to organisational change. Social science \& medicine, 72, 513-520. doi:10.1016/j.socscimed.2010.11.016

Mansfield, L., 2011. 'Sexercise': working out heterosexuality in Jane Fonda's fitness books. Leisure studies, 30 (2), 237-255. doi:10.1080/02614367.2010.523837

Markula, P., 1995. Firm but shapely, fit but sexy, strong but thin. The postmodern aerobicizing female bodies.

Sociology of Sport Journal, 12, 424-453.

Phoenix, C. and Grant, B.C., 2009. Expanding the agenda for research on the physically active aging body. Journal of Ageing and Physical Activity. 17 (3), 362-379.

Piggin, J., 2014. Designed to move? Physical activity lobbying and the politics of productivity. Health education journal, 74, 16-27.

Piggin, J. and Bairner, A., 2014. The global physical inactivity pandemic: An analysis of knowledge production. Sport education and society, 21, 131-147.

Waddington, I., 2000. Sport, health and drugs: A critical sociological perspective. Oxford: Taylor \& Francis.

Wilkinson, R.G. and Marmot, M.G., eds., 2003. Social determinants of health: the solid facts. Geneva: World Health Organization.

World Health Organisation (WHO), 2007. Working for health: an introduction to the World Health Organization. Geneva: WHO Switzerland.

Wray, S., 2007. Health, exercise, and well-being: the experiences of midlife women from diverse ethnic backgrounds. Social theory \& health, 5 (2), 126-144. doi:10.1057/palgrave.sth.8700100 